\title{
New geothermal well-completion and rework technology by laser
}

\author{
Péter Bajcsi ${ }^{1 *}$, Tamás Bozsó1, Róbert Bozsó ${ }^{1}$, Gábor Molnár1, Viktor Tábor ${ }^{2}$, \\ Imre Czinkota ${ }^{3}$, Tivadar M. Tóth ${ }^{3}$, Balázs Kovács ${ }^{3}$, Félix Schubert ${ }^{3}$, \\ Gábor Bozsó ${ }^{3}$, János Szanyi ${ }^{3}$
}

${ }^{1}$ ZerLux Hungary Ltd. Gödöllő, Hungary

${ }^{2}$ ANT Ltd., Budapest, Hungary

${ }^{3}$ Department of Mineralogy, Geochemistry and Petrology, University of Szeged, Szeged, Hungary

Received: January 28, 2015; accepted: January 28, 2015

\begin{abstract}
Our research team has developed a new well completion and rework technology involving lasers. The system is made up of a high-power laser generator and a custom-designed directional laser drilling head. The laser head is attached to a coiled tubing unit to maximize production and to carry out special downhole tasks. In this phase of the development effort, laser technology is particularly well suited to cost-efficiently drill short laterals from existing wells in a single work phase, drilling through the casing and cement as well as the formation. The technology, which is an extended perforation solution, enables a more intensive interaction with the downhole environment and supports cutting edge subsurface engineering scenarios such as barite removal. Laser-induced heat treatment appears to be a suitable alternative to effectively remove the almost immovable deposits and scales from thermal water-well pipes.
\end{abstract}

Keywords: laser drilling, geothermal well, yield efficiency, barite scale, scale removal

\section{Introduction}

Geothermal energy is widely known for its reliable, weather-independent and renewable nature, which is commonly used in many countries all over the world for power generation purposes as well as direct heat applications, as in Hungary where geothermal wells have been operating for over 140 years. While there are more than 600 production wells operating on porous thermal aquifers, only a few injection wells have been drilled into sandstone, as the direct use of thermal water without

\footnotetext{
* Corresponding author: Pattantyús Ábrahám körút 10, H-2100 Gödöllö, Hungary;

E-mail: info@zerlux.com
} 
reinjection has been standard procedure in Hungary (Szanyi and Kovács 2010). The safe reinjection of geothermal fluids into sandstone has posed very serious technical problems impeding the utilization of geothermal energy. The other problem during thermal water production is the frequent precipitation of hard scales in the production tubes of geothermal wells, which radically reduces the effective flow diameter of affected tubes. Some scale formations may totally plug up the pipe.

Our aim is to develop a novel well completion and scale removal technology for sustainable and cost-efficient thermal water production in the context of heating and generating electricity in addition to facilitating a variety of rework tasks by applying laser technology.

\section{Principles of laser drilling technology}

The first industrially-used lasers were developed for cutting metals in 1970. Later on more and more companies turned their attention toward developing lasers for use in industrial environments, as well as fluid mining (Augustine 2009; Saudi Aramco 2009).

Our research team has developed a cost-efficient and environmentally safe technology in subsurface laser drilling. Our High Power Laser Device (HPLD) utilizes cutting-edge, underbalanced laser well completion and rework technology applicable in fluid mining, including the geothermal industry. The system comprises a high-power laser generator and a specially designed directional laser drilling head. The laser head is attached to a coiled tubing system, to maximize production by directionally drilling short laterals into the formation. The laser head uses nitrogen to displace all fluids during the drilling process. This prevents contamination of the formation by drilling mud and facilitates unimpeded flow through the borehole. The HPLD requires low maintenance, does not contain any mechanical parts subject to wearing out or any chemical substances, and fits into existing drilling equipment while offering an in situ, real-time controlled procedure with video and spectroscopy feedback to the operator.

In this phase of the development effort laser technology is especially well suited to cost-efficiently drill short laterals from existing wells in any desired direction in a single work phase, while drilling through the casing and cement as well as the formation, with a single tool in and out of the well, maintaining formation integrity and environmental safety. The diameter of the individual laterals may vary between 1-3 inches and their length can be as long as 100 feet. The HPLD will superheat the subsurface formation, melt the target material and will remove the molten debris while the borehole is being drilled (Fig. 1). The technology allows the operator to adjust the permeability of the borehole wall (between permeable and non-permeable). The result of this process is a highly permeable lateral pointing at any desired direction (Fig. 2), with a large active surface to increase either water production or injection yields. Note that impermeable lateral segments can also be formed. 

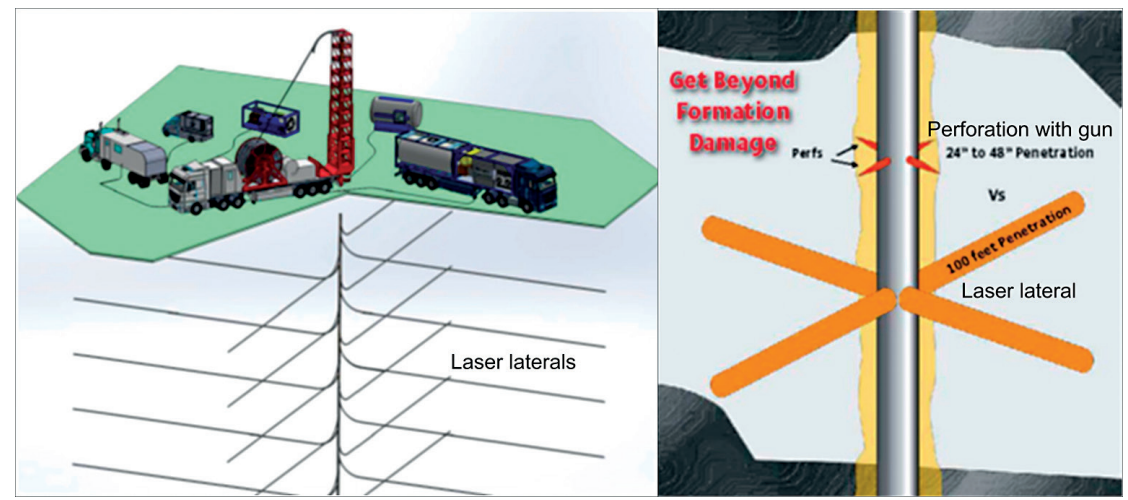

Fig. 1

Schematic figure of High Power Laser Device and laser laterals versus traditional perforations with perforation gun

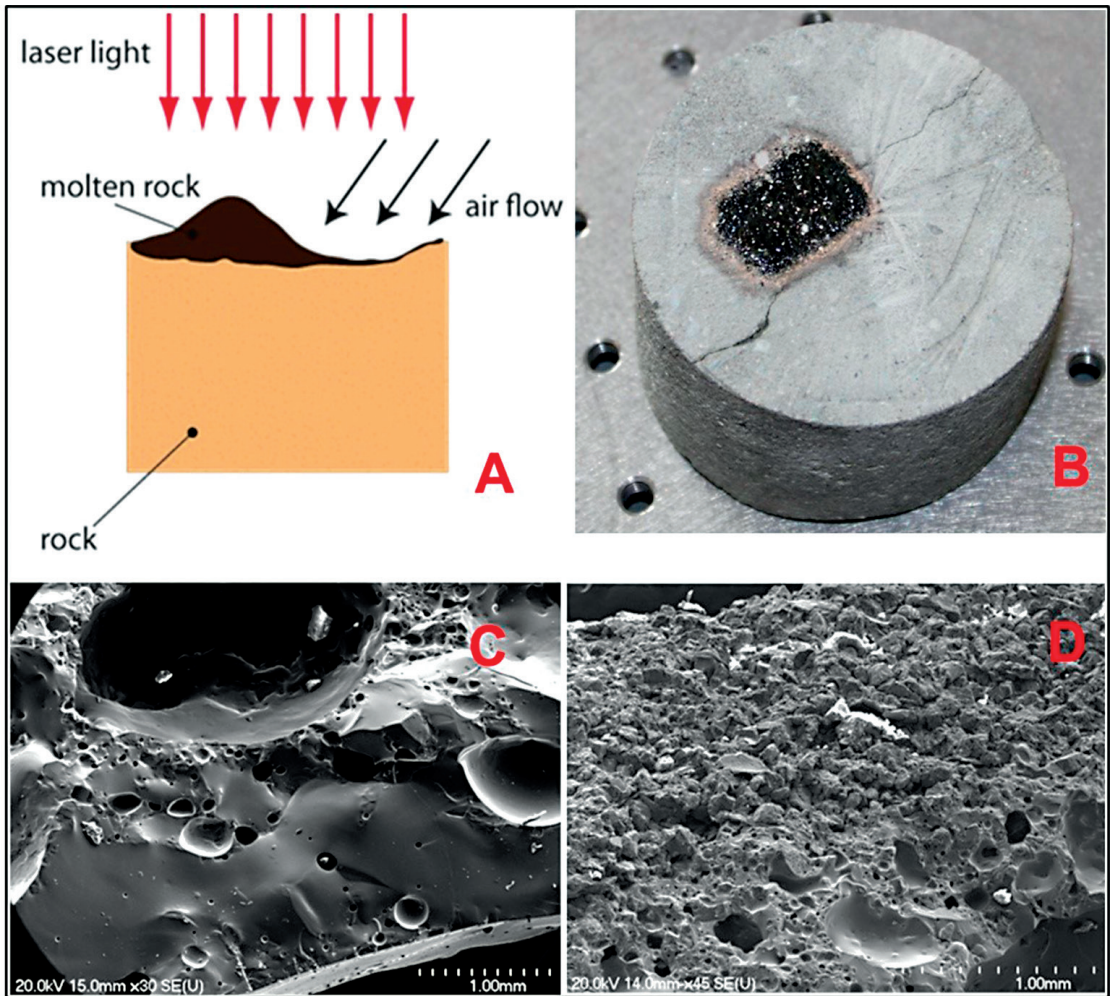

Fig. 2

A) rock melting and removal by laser; B) sandstone sample with molten glass layer; C) sealed glass layer (non-permeable); D) open glass layer with microchannels (permeable) 
The other use of the HPLD is scale (including barite) removal without affecting pipe integrity. Several patented solutions are known for the task of removing such scales, sometimes with mechanical impact (Brown et al. 1991) and sometimes with chemical treatments (Nasr-El-Din et al. 2004). These methods offer a lesser, rather than greater, chance of success. Thermal decomposition and removal by laser, however, is a possibility for every salt deposit. Carbonates begin to thermally decompose in a solid phase at a temperature range of approximately 1,000 K. For sulfates this temperature range is close to the melting point or above.

\section{Potential use of HPLD drilling technology and its benefits}

This new technology is fitted to several specific applications, such as:

- Well completion: increased drainage area resulting in low pressure gradient;

- Geothermal water re-injection;

- Rework: decreased water coning effect;

- Finding and precisely adding new intervals in depleted reservoirs;

- Drilling in thin reservoirs where hydraulic fracturing would carry high risk;

- Underground coal gasification: exploration and analysis;

- Coal-bed methane: exploration and analysis;

- $\mathrm{CO}_{2}$ sequestration;

- Exploratory drilling: real-time formation analysis during drilling;

- Scale removal without affecting pipe integrity, including barite deposits;

- Nanno-mining, zero gravity mining,

The technology affords the following technical benefits:

- Non-mechanical drilling;

- Real time in situ analysis (absorption and emission spectroscopy, video imaging);

- Small umbilical diameter (1.5 inch) enables platform application and low-cost transportation;

- Small, compact size, easily transported;

- Reliable and long lifetime (15,000 hours);

- Low cost of additional components used in the well;

- No mechanical formation damage;

- No formation contamination ( $\mathrm{N}_{2}$ as assist gas);

- Increased flow efficiency (see Fig. 2).

\section{Permeability investigations}

The permeability tests were performed on core samples (mostly sandstone and siltstone) using radial infiltration. At first a small diameter hole of 8-10 mm was drilled into the centerline (axis) by traditional drilling. The permeability of the sam- 
ples was tested in air, organic fluid and water. The organic fluid consisted of short carbon-chain aliphatic hydrocarbons of a constant mixing ratio. Before, in between and after the tests the elimination of fluid from the pores due to vaporization was established by measuring the mass of the samples.

After testing the original samples, they were laser-treated by the HPLD. A laser device with $1.5 \mathrm{~kW}$ laser beam power was applied until a hole of the required size was formed. After laser treatment the permeability of the samples was once more measured using air, organic liquid and water. The tests were completed at constant hydraulic gradient (constant head) for seven repeated measurements using 50-200 kPa overpressure in the pressure container so that the average permeability of the sample could be established. The overpressure applied was the reverse of the average permeability of the samples; the requisite overpressure range had to be precisely identified to minimize measurement error. The circular walls of the samples (top and bottom) were clogged by using highly deformable silicon plates and plastic silicon gel. This ensured that infiltration from the chamber could only happen on the side-walls. The mechanically or laser-drilled holes formed the drainage path from where the liquid or the air was led out and its volume was continuously measured (Kovács et al. 2014).

The permeability of several hundreds of samples was measured. The permeability of the original samples that were collected from the lowest permeability sections of the sandstone reservoir were measured in the range of $0.01-200 \mathrm{mD}$.

Surprisingly enough, the average permeability of the samples increased by a factor of 1.5 to 4 after laser treatment (Fig. 3). In some cases discrete fractures could be observed in radial directions but there were several samples where only invisible mi-

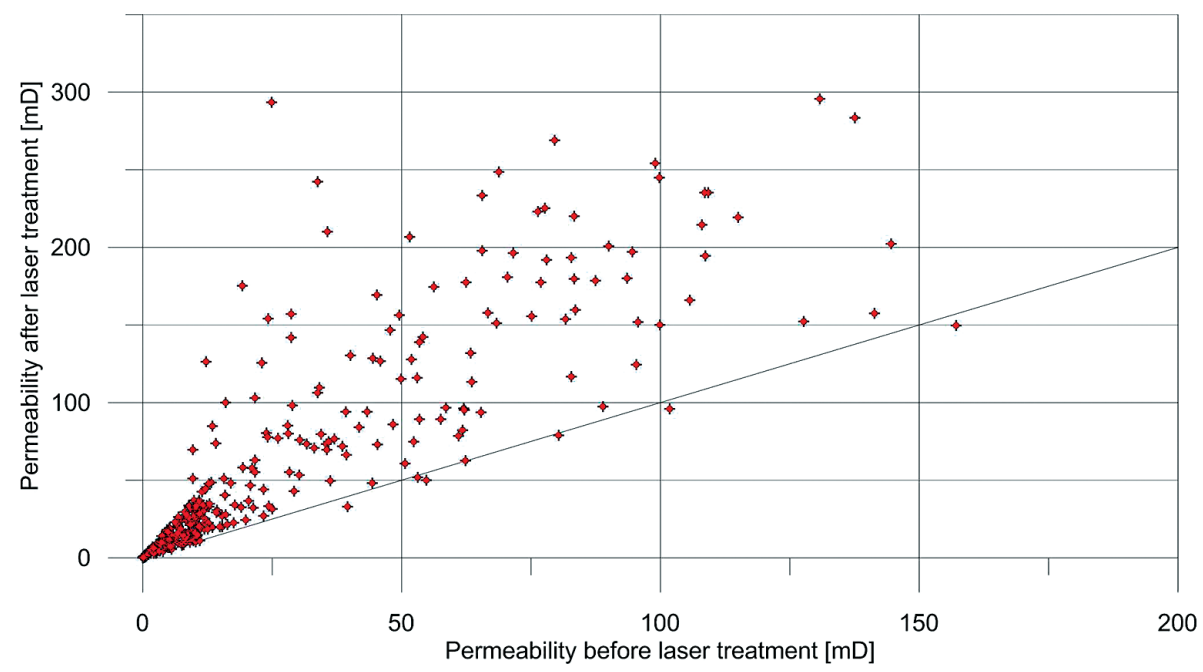

Fig. 3

Induced permeability increase is due to heat shock fracturing caused by laser drilling 
cro-fissures were formed by the laser treatment. The increased permeability was due to the matrix as well as to the fractures; therefore this was considered to be induced permeability (Kovács et al. 2014).

\section{Calculation of flow efficiency}

We have calculated the fluid yields from laser-drilled completions versus traditional perforation. From the permeability investigations introduced above, it was assumed that the permeability of the laser-drilled lateral walls is similar to the permeability of the original rock matrix.

The well and the reservoir were assumed to have the following properties for calculation:

- Perforations $=6 \operatorname{spf}(6$ shots per foot of interval $), 60$ degree phasing $\left(60^{\circ}\right.$ between each adjacent perforation), 1.5 foot depth of penetration, perforation diameter of 0.3 inches, $20 \%$ crushed zone permeability extending to depth of 0.5 inches;

- Drilling damage of $50 \%$ extending to 6 inches into the formation;

- Original open hole size diameter of 6 inches;

- For the laterals, the initial comparison had no crushed zone, a diameter of 2 inches, variable lateral length and 1 lateral every 2 feet $(0.5 \mathrm{spf})$. Phasing was also $60^{\circ}$.

- Vertical to horizontal permeability ratio: $\mathrm{K}_{\mathrm{v}} / \mathrm{K}_{\mathrm{h}}=0.01$.

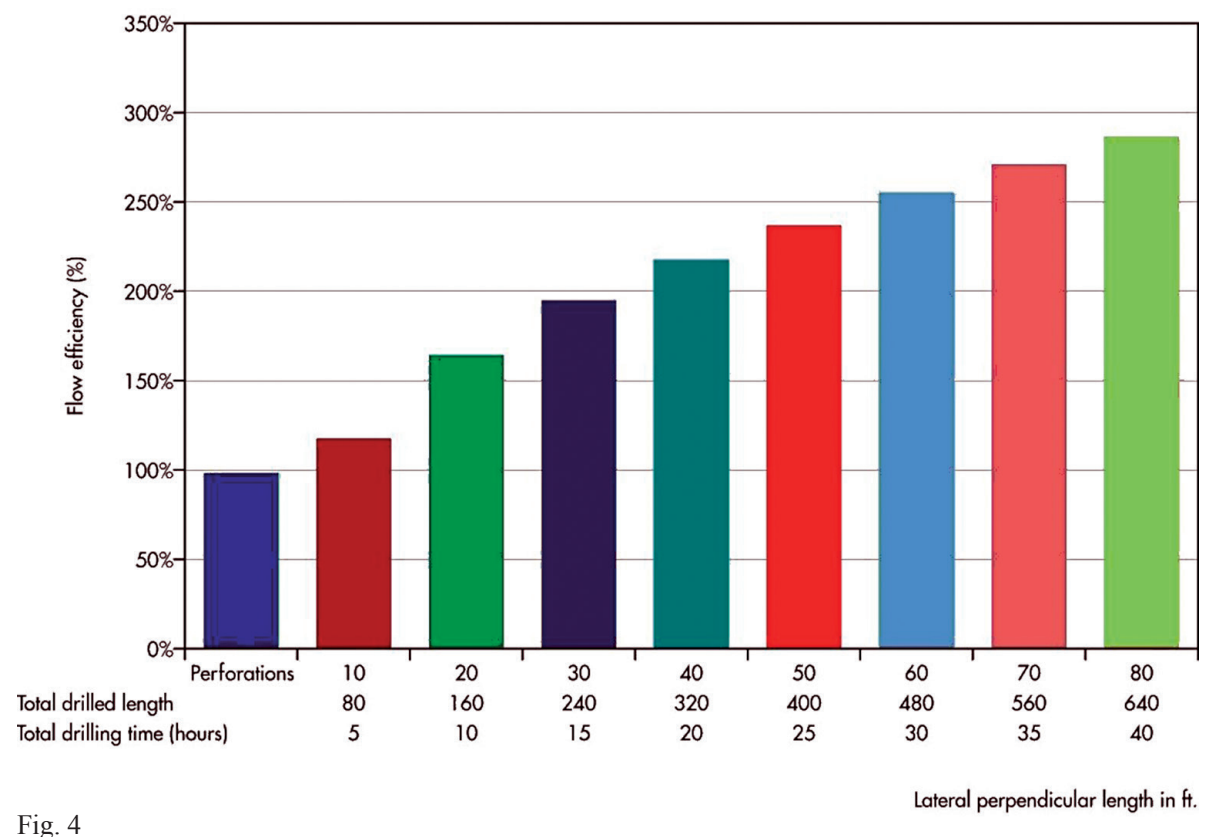

Fig. 4

Flow efficiency - comparison of perforating versus laser drilled laterals 
Our calculations indicated that laser-drilled short lateral perforations increased the yield or the injectivity of thermal wells by potentially up to $250 \%$, compared with existing technologies used in hydrothermal reservoirs (Fig. 4).

\section{Scale removal by laser}

Alkaline-earth elements are practically insoluble in water and are consequently likely to produce scale precipitates in pipes. Typical examples of such scales include $\mathrm{CaCO}_{3}, \mathrm{SrCO}_{3}, \mathrm{BaCO}_{3}, \mathrm{CaSO}_{4}, \mathrm{SrSO}_{4}$, and $\mathrm{BaSO}_{4}$ crystals, often mixed with various amounts of $\mathrm{SiO}_{2}$ substances. The most frequent scale-forming materials are $\mathrm{CaCO}_{3}$, and $\mathrm{BaSO}_{4}$ (Bellarby 2009) due to their high insolubility. Carbonate salts become soluble through acidic treatment. Sulfate salts, however, require very high temperatures and a reductive environment to become soluble. Barium-sulfate precipitates are an especially frequent occurrence in mineral waters containing sulfate ions (Quddus and Allam 2000). Our investigation focused on barite scales.

\section{Materials and methodology}

We used the following mixture samples for experiments:
A) $100 \% \mathrm{BaSO}_{4}$,
B) $75 \% \mathrm{BaSO}_{4}+25 \% \mathrm{CaSO}_{4}$,
C) $50 \% \mathrm{BaSO}_{4}+25 \% \mathrm{CaSO}_{4}+25 \% \mathrm{CaCO}_{3}$,
D) $50 \% \mathrm{BaSO}_{4}+25 \% \mathrm{CaSO}_{4}+25 \% \mathrm{SiO}_{2}$.

The powder mixture was inserted into an aluminum tube with a diameter of 25 $\mathrm{mm}$ and a length of $100 \mathrm{~mm}$, and was compacted. The samples were impinged by laser light for a duration of 1 minute with an SLD-B 850 infra-red laser with an electric capacity of $3 \mathrm{~kW}$ and light capacity of $850 \mathrm{~W}$, with a wavelength of $915 \mathrm{~nm}$. The solid lumps were removed after melting and were cleaned of the original powder. We measured the mass of the molten substance and determined the mineralogical composition immediately by X-ray diffractometry (XRD). To analyze the thermal decomposition of the molten substance we extracted samples of 5-5 g; $100 \mathrm{~cm}^{3} 0.1$ $\mathrm{mol} / \mathrm{dm}^{3} \mathrm{KCl}$ solutions and $0.1 \mathrm{~mol} / \mathrm{dm}^{3} \mathrm{HNO}_{3}$ solutions were added, respectively. After 2 hours of shaking, a $10 \mathrm{ml}$ aliquot of the clear solution was titrated with 0.1 $\mathrm{mol} / \mathrm{dm}^{3} \mathrm{HCl}$ from the $\mathrm{KCl}$ extract and $0.1 \mathrm{~mol} / \mathrm{dm}^{3}$ of $\mathrm{NaOH}$ solution from the $\mathrm{HNO}_{3}$ extract. Methyl orange indicators were used. The extracted $\mathrm{Ba}$ concentration was measured by flame emission spectrometry. The Ca concentration was measured by atomic absorption spectrometry. We replicated the tests three times. 


\section{Results and evaluation}

Only the original powder mix was in continuous contact with the molten substance. Consequently, the quantity of the initial state powder mix could not affect the quantity of the substance melted by the laser. To assess the efficiency of the melting process we used the measured molten substance mass of the different compositions (see data in Table 1 and Fig. 5).

Table 1

Soluble Ba content in different mixtures

\begin{tabular}{lllll}
\hline Marking and composition of sample & $\begin{array}{l}\mathrm{Ba} \text { content, } \\
\mathrm{g} / \mathrm{kg}, \mathrm{HNO}\end{array}$ & $\begin{array}{l}\text { Variance, } \\
\mathrm{g} / \mathrm{kg}\end{array}$ & $\begin{array}{l}\mathrm{Ba} \text { content, } \\
\mathrm{g} / \mathrm{kg}, \mathrm{KCl}\end{array}$ & $\begin{array}{l}\text { Variance, } \\
\mathrm{g} / \mathrm{kg}\end{array}$ \\
\hline A) $100 \% \mathrm{BaSO}_{4}$ & 79.3 & 5.1 & 46.4 & 10.4 \\
\hline B) $75 \% \mathrm{BaSO}_{4}+25 \% \mathrm{CaSO}_{4}$ & 33.3 & 1.1 & 0.6 & 0.1 \\
\hline C) $50 \% \mathrm{BaSO}_{4}+25 \% \mathrm{CaSO}_{4}+25 \% \mathrm{CaCO}_{3}$ & 5.0 & 0.1 & 7.2 & 0.3 \\
\hline D) $50 \% \mathrm{BaSO}_{4}+25 \% \mathrm{CaSO}_{4}+25 \% \mathrm{SiO}_{2}$ & 20.9 & 5.8 & 28.8 & 0.4 \\
\hline
\end{tabular}

The left side of Fig. 5 shows that there appeared to be significant differences between the mass of molten substance in particular mixtures. At a given laser light energy level the barite sample produced the largest amount of molten substance. The smallest amount was produced by the sample containing $\mathrm{SiO}_{2}$. The data also confirm that calcite will facilitate the generation of molten substance.

Uncontaminated barium sulfate will decompose at a temperature not much lower than its melting point $\left(\sim 1,580{ }^{\circ} \mathrm{C}\right)$, according to the following reactions:

$\mathrm{BaSO}_{4}=\mathrm{BaO}+\mathrm{SO}_{3}$, and $\mathrm{BaSO}_{4}=\mathrm{BaO}_{2}+\mathrm{SO}_{2}$

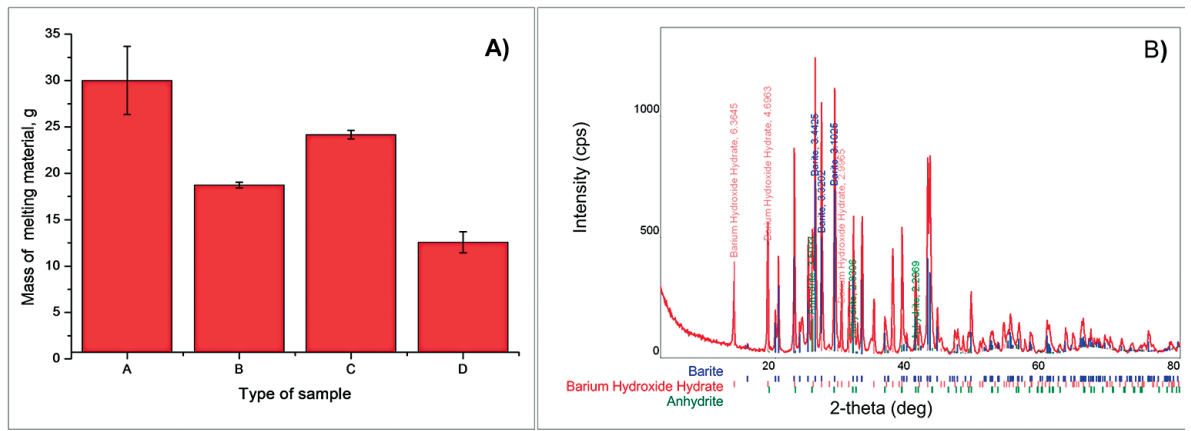

Fig. 5

A) mass of molten substance of particular mixtures; B) XRD spectrum, sample of $75 \% \mathrm{BaSO}_{4}$ and $25 \%$ $\mathrm{CaSO}_{4}$ after laser light treatment 
The resulting oxide and peroxide will react with water according to the following reactions:

$\mathrm{BaO}+\mathrm{H}_{2} \mathrm{O}=\mathrm{Ba}(\mathrm{OH})_{2}$, and $\mathrm{BaO}_{2}+2 \mathrm{H}_{2} \mathrm{O}=\mathrm{Ba}(\mathrm{OH})_{2}+\mathrm{H}_{2} \mathrm{O}_{2}$

Similar reactions apply to calcium compounds as well.

To follow the decomposition we used the XRD pattern of the molten substance. The spectrum reading (Fig. $5 \mathrm{~B})$ indicated the presence of barite $(\sim 70 \%)$, anhydrite $(\sim 15 \%)$, and barium-hydroxide $(\sim 15 \%)$. These results harmonize well with the anticipated decomposition reactions. The measurements were made two days after the laser treatment, and the water in the air induced the emergence of hydroxides.

In addition to semi-quantitative XRD measurements we also used fully quantitative measurements to measure the concentration of decomposed (and hence soluble) barium and calcium in the molten substance. Two different solutions were used to extract the calcium and barium compounds from the molten substance as they had chemically changed and become soluble. We used a $0.1 \mathrm{~mol} / \mathrm{dm}^{3} \mathrm{KCl}$ solution in a neutral environment to extract the water-soluble compounds, primarily aimed at the generated hydroxides. Some $0.1 \mathrm{~mol} / \mathrm{dm}^{3}$ nitric acid was applied to dissolve the acid-soluble compounds, which were primarily carbonates. The calcium and barium hydroxide compounds react with the carbon-dioxide of the air and generate water-insoluble carbonates, which, however, are very easy to dissolve in light acids. Having been exposed to the air prior to the measurements, the samples could easily form carbonates, which meant that acidic extraction was a reasonable action.

Having measured the barium and calcium concentration of the extracts, we determined the quantity of the soluble metallic ions. This also allowed us to calculate the soluble ion content of the original molten substance (Fig. 6). The largest amount of soluble barium ion was obtained from clean barite.
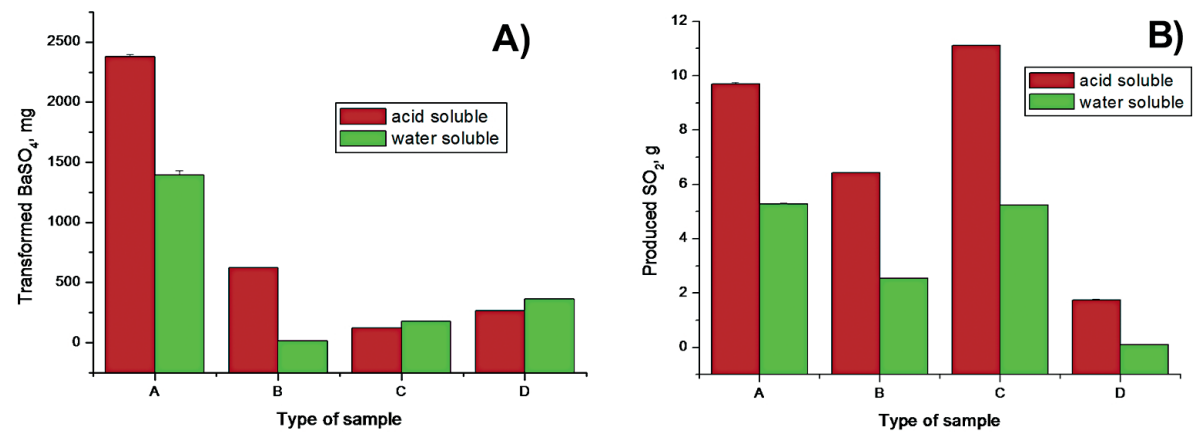

Fig. 6

A) total quantity of decomposed sulfates expressed in $\mathrm{BaSO}_{4}$; B) Gas state sulfur compounds calculated from alkalinity, expressed in $\mathrm{SO}_{2}$ 
It is important to note that in the $25 \% \mathrm{CaSO}_{4}$ sample the water-soluble barium concentration decreased over its proportionate rate. This could possibly mean that heating the substances together will decompose the $\mathrm{CaSO}_{4}$ more effectively than anything else, although confirming this requires additional experiments. Intriguingly, glass was created in the sample that included silicon dioxide but the soluble barium concentration failed to substantially decrease.

The equations presented above show that decomposition will cause sulfur oxides (sulfur dioxide and sulfur trioxide) to leave the system. To identify them we used titration, relying on the fact that the absence of sulfur oxide will cause the substance to turn alkaline.

With the $\mathrm{KCl}$ solution we simply titrated the extract with acid and measured the amount of departing sulfur dioxide. With the acidic extraction the extracting agent was titrated with alkaline and the absence of the acid content was identified by the alkalinity of the sample: that is to say with the equivalent quantity of the generated sulfur dioxide. The quantity of the molten material and the measured barium concentrate allows us to calculate the total quantity of the barium sulfate, either decomposed or transformed by the particular dosage of laser energy. The titrated hydroxide quantity permits us to calculate the total quantity of sulfur dioxide generated by the particular amount of laser energy (also expressed as sulfur dioxide/sulfur trioxide). This is shown in Fig. 6.

At a given energy level impingement, the largest amount of soluble barium ions was obtained from clean barite. The smallest quantities were produced by samples that contained roughly equal amounts of carbonate and silicon dioxide. The bariteanhydrite mixture results showed a substantial degree of carbonate generation. It is clear that clean barite produces a significantly larger amount of sulfur dioxide than barite-anhydrite mixtures do. The values were significantly higher with the sample that also contained carbonate. However, in this case the departing carbon dioxide was also counted into the sulfur dioxide quantity. This is why the results from nitric acid shaking are immaterial with the $\mathrm{C}$ sample. The $\mathrm{D}$ sample shows the significant impact of silicon dioxide as we cannot use alkalinity to measure the evaporating

Table 2

Efficacy of $\mathrm{BaSO}_{4}$ melting and decomposing as a function of sample composition

\begin{tabular}{lllll}
\hline Marking and composition of sample & $\begin{array}{l}\text { Melting } \\
\text { efficacy, } \\
\mathrm{mg} / \mathrm{kJ}\end{array}$ & $\begin{array}{l}\text { Variance, } \\
\mathrm{mg} / \mathrm{kJ}\end{array}$ & $\begin{array}{l}\text { Decomposition } \\
\text { efficacy, } \\
\mathrm{mg} / \mathrm{kJ}\end{array}$ & $\begin{array}{l}\text { Variance, } \\
\mathrm{mg} / \mathrm{kJ}\end{array}$ \\
\hline A) $100 \% \mathrm{BaSO}_{4}$ & 588.2 & 71.92 & 46.65 & 0.367 \\
\hline B) $75 \% \mathrm{BaSO}_{4}+25 \% \mathrm{CaSO}_{4}$ & 367.3 & 5.81 & 12.23 & 0.006 \\
\hline C) $50 \% \mathrm{BaSO}_{4}+25 \% \mathrm{CaSO}_{4}+25 \% \mathrm{CaCO}_{3}$ & 473.8 & 9.22 & 2.37 & 0.001 \\
\hline D) $50 \% \mathrm{BaSO}_{4}+25 \% \mathrm{CaSO}_{4}+25 \% \mathrm{SiO}_{2}$ & 246.4 & 22.25 & 5.15 & 0.129 \\
\hline
\end{tabular}


sulfur dioxide. The explanation for this is that the alkaline earth compounds that emerged during glassification ceased to be alkaline, while the sulfates were decomposed, producing sulfur dioxides.

From the known amount of the energy applied, we can calculate the melting and transformation (decomposition) efficiency (Table 2). Obviously barite has the best efficiency while the worst one was measured in the sample containing $\mathrm{SiO}_{2}$. The worst decomposition efficiency was measured in the sample containing $\mathrm{CaCO}_{3}$.

\section{Conclusions}

Measurements indicate that laser drilled short laterals can help to maintain reservoir integrity and increase productivity.

In geothermal well completion and rework operations laser energy offers distinct advantages. Since laser drilling is non-mechanical, it can be easily steered and controlled and integrated into coiled tubing systems.

The laser head uses nitrogen to displace all fluids during the drilling process. This prevents the contamination of the formation by drilling mud and facilitates unimpeded flow through the borehole. The technology is especially suitable for reinjection wells in porous formations as the highly porous glass will serve as a filter and will also prevent the flowing fluids from ripping particles off the borehole wall.

We used samples containing $\mathrm{BaSO}_{4}, \mathrm{CaSO}_{4}, \mathrm{CaCO}_{3}$, and $\mathrm{SiO}_{2}$ mixed at various ratios. The samples were impinged by $850 \mathrm{~W}$ infrared laser light for a duration of one minute. We saw that melting led to sulfate decomposition and generated oxides and hydroxides. The largest amount of molten substance was produced by clean barite and the smallest quantities came from the samples containing silicon dioxide.

In all sample compounds it was clear that laser-induced melting prompted the originally water insoluble alkaline earth sulfates to decompose into water soluble hydroxides and gas state water-soluble sulfur dioxide.

The results of the experiments indicate that if the appropriate mechanical solution is unavailable, laser induced heat treatment is a suitable alternative to effectively remove the otherwise almost immovable deposits and scales from thermal water well pipes.

Deployment of laser drilling may outperform current reservoir stimulation technologies in improved productivity for existing and new deep geothermal resources.

\section{References}

Augustine, C.R. 2009: Hydrothermal spallation drilling and advanced energy conversion technologies for Engineered Geothermal Systems. - PhD thesis, 333 p., http://hdl.handle.net/1721.1/51671.

Bellarby, J. 2009: Well Completion Design. - Elsevier, Amsterdam, pp. 378-390. 
Brown, A.D.F., S.J. Merrett, J.S. Putnam 1991: Coil-Tubing Milling/Underreaming of Barium Sulphate Scale and Scale Control in the Forties Field. - SPE Offshore Europe Conference, Aberdeen, 17 p.

Kovács, B., I. Czinkota, J. Szanyi, T. Bozsó, M. Tóth, L. Busuttil 2014: The permeability of laser drilled laterals in sandstone reservoirs. - Geosciences and Engineering, 3/5, pp. 83-93.

Nasr-El-Din, H.A., S.H. Al-Mutairi, H.H. Al-Hajji 2004: Evaluation of a New Barite Dissolver: Lab Studies. - SPE International Symposium and Exhibition on Formation Damage Control, Lafayette, $11 \mathrm{p}$.

Quddus, A., I.M. Allam 2000: $\mathrm{BaSO}_{4}$ scale deposition on stainless steel. - Desalination, 127, pp. $219-224$.

Saudi Aramco 2009: Saudi Aramco breaks new ground with in-situ laser perforation. - http://www. rigzone.com.

Szanyi, J., B. Kovács 2010: Utilization of geothermal systems in South-East Hungary. - Geothermics, 39, pp. 357-364. 